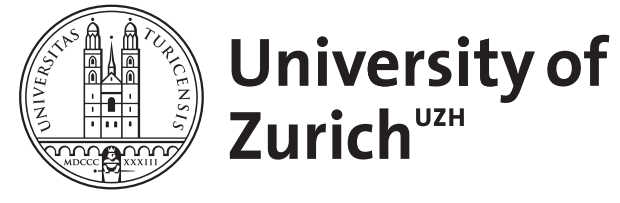

\title{
Über das Erinnern und das Vergessen
}

Wolff, Eberhard

Abstract: Demenz macht Angst, weil sie mit Kontroll- und Orientierungsverlust einhergeht. Das grosse Vergessen hat aber nicht nur eine Schreckensseite.

Posted at the Zurich Open Repository and Archive, University of Zurich ZORA URL: https://doi.org/10.5167/uzh-92280

Journal Article

Published Version

Originally published at:

Wolff, Eberhard (2013). Über das Erinnern und das Vergessen. Schweizerische Aerztezeitung, 94(22):858. 


\section{Über das Erinnern und das Vergessen}

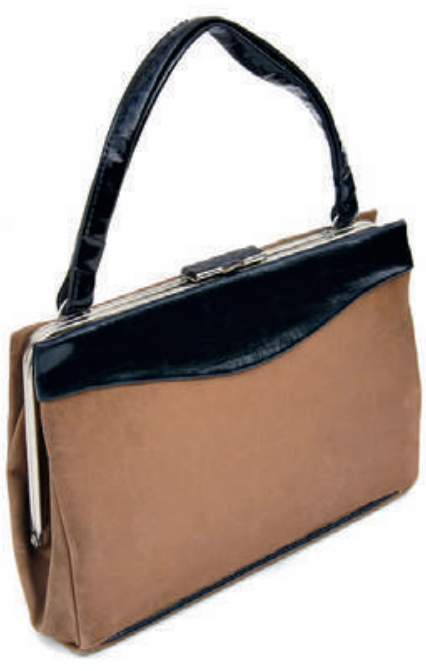

«Die Gedanken sind frei», singt die Patientengruppe auf der Station des Pflegeheims im deutschen Duisburg. Es ist nicht wirklich die Art Pflegeheim, die man sich selber für die letzte Phase seines Lebens wünscht. Eine freie Gedankenreise kann in einer solchen Umgebung guttun. Ich weiss von mir selbst, wie sehr so eine Übung in einem unwirtlichen Umfeld die eingezwängten Gefühle zu befreien vermag.

Auch die Patientin Frau Mauerhoff versucht mitzusingen. Aber ihre Gedanken sind nicht mehr frei, sie kann sich mit ihren Gedanken auch nicht mehr befreien. Frau Mauerhoff hat Demenz im für sie leidund angstvollen mittleren Krankheitsstadium, wenn die kurze und mittlere Erinnerung verlorengeht.

Eva Mauerhoff ist die Hauptperson des preisgekrönten Films «Der Tag, der in der Handtasche verschwand» [1] der Dokumentarfilmerin Marion Kainz aus dem Jahr 2000. Der Film folgt Frau Mauerhoff in eindrucksvoller dokumentarischer Einfühlsamkeit, wie sie orientierungslos, verwirrt und verängstigt durch die Gänge läuft, den Ausgang sucht. «Kann ich nicht irgendwo hingehen und fragen, ob man mich kennt, damit ich Anhaltspunkte habe?», fragt sie verstört. Sie will nach Hause gehen und weiss nicht, wohin, sie erinnert sich an ihr Zuhause nicht mehr und sucht den letzten Tag in ihrer Handtasche. Frau Mauerhoff ist gefangen in den immer engeren Grenzen, die ihr das eigene Hirn setzt.

Demenz ist derzeit ein heisses Thema. Der medizinische Mabuse-Buchversand in Deutschland zum Beispiel bietet dreihundert einschlägige Titel an. Demenz spiegelt sich in Romanen wie Martin Suters «Small World» bis hin zu Kinofilmen wie kürzlich David Sievekings «Vergiss mein nicht». Ein Thema zwischen der Medizin und den Kultur- und Gesellschaftswissenschaften. Im Zürcher Kirchgemeindehaus Enge diskutierten kürzlich Fachleute auf Einladung der Schweizerischen Gesellschaft für Kulturwissenschaften Aspekte von Demenz, Erinnern und Vergessen im Umfeld des Handtaschen-Films.

Die grosse Medienabdeckung ist für den Literaturwissenschaftler Rudolf Käser (Universität Zürich) auch Ausdruck der Angst vor der Krankheit. Und für Albert Wettstein, Vizepräsident der Alzheimervereinigung im Kanton Zürich und ehemaliger Zürcher Stadtarzt, leistet der kulturelle Umgang mit der Krankheit einen Beitrag, indem eine Sprache entwickelt wird, mit den Herausforderungen umzugehen und sie zu verarbeiten.

Demenz ängstigt uns auch, weil sie etwas zerstört, was für uns heute von immer grösserer Bedeutung ist: das Leben im Griff zu haben. Man verliert die Kontrolle über sich und sein Leben, man verliert seine Orientierung und damit schliesslich auch seine Autonomie und Freiheit. Das Erinnern, das mit der Demenz immer mehr verlorengeht, ist ein Fundament, auf dem diese Werte gebaut sind.

«Welcher Tag ist heute?» Bis vor einiger Zeit wurde versucht, so Wettstein, dem Vergessen mit einem Training in Realitätsbezug entgegenzusteuern, was die Unruhe der Patienten eher vergrösserte. Genau dies spiegelt sich laut Käser auch in der Machart Handtaschen-Film: Alzheimer wird als eine Art «Vorhölle» gezeichnet. Derzeit liegt der Schwerpunkt der Betreuung eher darauf, den Betroffenen Vertrautheit zu ermöglichen: Patienten sollten genug Zeit haben, um sich an einen neuen Wohnort gewöhnen zu können. Vertrautheit entsteht über emotionale Bezüge: Räume, Gesichter, Beziehungen, Berührungen. Auch Lieder, die noch tief genug im Gedächtnis eingegraben sind, können Vertrautheit schaffen. Ein Tipp von Albert Wettstein: Besuchen Sie Patienten regelmässig, kündigen Sie den nächsten Besuch an und bringen Sie ein Foto von Ihnen als Geschenk mit.

Aber auch das Gefühl der Vertrautheit kommt oft nicht ohne ein Stück basaler Erinnerung aus, seien es nun Gesichter, Stimmen, Gerüche. Erst in der letzten Krankheitsphase leben die Menschen nur noch in der Gegenwart.

\section{Das grosse Vergessen hat also nicht nur eine Schreckensseite.}

Das grosse Vergessen hat also nicht nur eine Schreckensseite. Zudem, so die Seelsorgerin Elisabeth Flach vom Pflegezentrum Entlisberg: «Die Patienten verlieren Grenzen, also Hemmungen, da verändert sich das Verhalten von Personen sehr stark. Es gibt mehr Nähe, andere Zugänge, wie eben über Lieder, Rituale, Gebete.» Ein sekundärer Krankheitsgewinn. Und das neue Bild der Demenz spiegelt sich auch in den Medien wider, so Käser. Siehe zum Beispiel den Film «Vergiss mein nicht». Weniger Angst also und mehr Perspektiven?

Eberhard Wolff*

1 www.der-tag-der-in-der-Handtasche-verschwand.de 